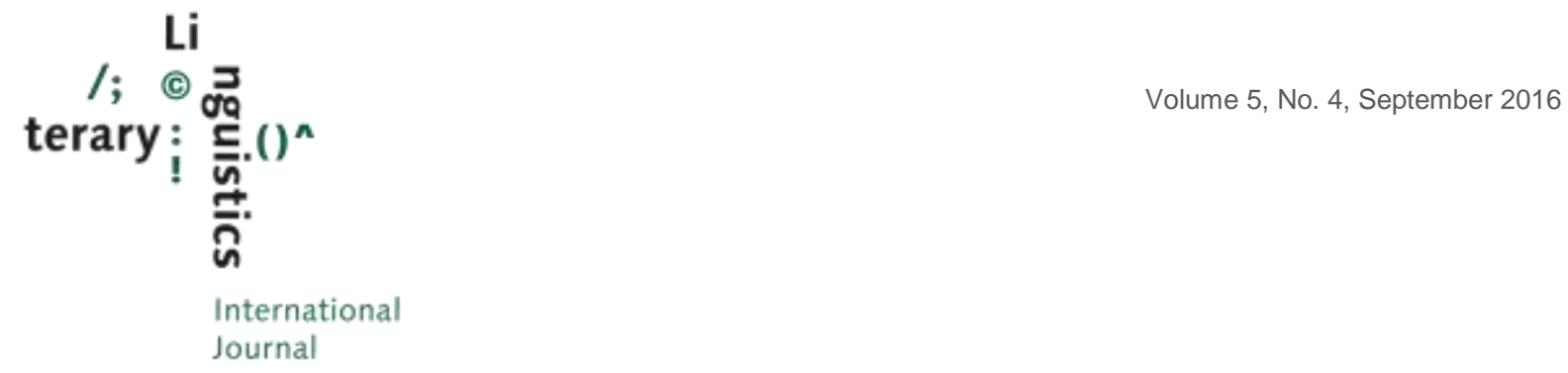

\title{
Processing Effort and Poetic Closure
}

Nigel Fabb, University of Strathclyde

Keywords:

Closure, expectation, Gestalt theory, metre, poetic form, processing, effort, relevance theory, tension
Abstract: Smith (1968) argues that poems may end with formal changes which produce an experience of closure in the reader. I argue that formal changes do not directly cause an experience of closure. Instead, changes in poetic form always demand increased processing effort from the reader, whether they involve new forms, shifts from more to less regular form, or from less to more regular form. I use relevance theory (Sperber and Wilson 1995) to argue that the increased processing effort encourages the reader to formulate rich and relevant thoughts, including the thought 'this poem has closure'. Closure is thus the content of a thought rather than a type of experience. I further argue that 'closure' is a term whose meaning cannot be fully understood, which makes the thought 'this poem has closure' into a schematic belief of the kind which Sperber shows has great richness and productivity. This is one of the reasons that the thought 'this poem has closure' achieves sufficient relevance to justify the effort put into processing the end of the poem.

\section{Introduction}

Barbara Herrnstein Smith, in her 1968 book Poetic Closure: a Study of How Poems End, suggests that we are able to know poems as wholes, and that poems can end in ways which produce in us a sense of 'closure'. For Smith, closure is a distinct kind of experience which is caused both by formal aspects of a poem and by thematic aspects of the poem.

We tend to speak of conclusions when a sequence of events has a relatively high degree of structure, when, in other words, we can perceive these events as related to one another by some principle of organization or design that implies the existence of a definite termination point. Under these circumstances, the occurrence of the terminal event is a confirmation of expectations that have been established by the structure of the sequence, and is usually distinctly gratifying. The sense of stable conclusiveness, finality or "clinch" which we experience at that point is what is referred to here as closure. (Smith 1968: 2)

She says that closure is a "sense of finality, stability, and integrity" and "depends primarily upon the reader's experience of the structure of the entire poem" (Smith 1968: viii). Smith makes two claims, that closure is a distinct type of experience, and that the experience of closure arises when formal changes at the end of the text manipulate the reader's expectations. 
In this paper I argue against both of these claims. I accept Smith's proposal that the changing forms of a poem can cause changes in our reading of the poem, and particularly at the end of the poem, and that these changes relate to a sense of closure. However, I propose that the sense of closure is not a type of experience but instead that the sense of closure is part of the content of a thought about the poem. This thought is an inference derived by processes described by relevance theory (Sperber \& Wilson 1995). The thought that 'this poem has closure' is neither a direct response to specific formal changes nor caused by those formal changes. The causal chain is less direct and determinate, and begins when the formal changes cause an increase in processing effort. Relevance theory tells us that if a communicative act such as a poem forces an increase in processing effort then the poem also guarantees an increase in cognitive effects. The thought that 'this poem has closure' is a cognitive effect which adequately rewards the increase in processing effort which was caused by the processing of the formal changes.

\section{Smith's theory of closure}

\subsection{Expectation}

For Smith, formal changes in a poem have an effect on a reader because the reader formulates expectations which are then satisfied.

Poetic structure is, in a sense, an inference which we draw from the evidence of a series of events. As we read the poem, it is a hypothesis whose probability is tested as we move from line to line and adjusted in response to what we find there. And, as the illustrations suggest, the conclusion of a poem has special status in the process, for it is only at that point that the total pattern - the structural principles which we have been testing - is revealed. (Smith 1968: 13)

Thus Smith proposes that we formulate expectations about poetic form. There is some indirect evidence that we might formulate expectations that involve poetic form, though over short distances. For example, hearing a particular type of syntactic structure makes a person more likely to use it in a subsequent sentence (Sakita 2006: 487; Sturt, Keller \& Dubey 2010). This syntactic priming has been demonstrated for conversation and (though I do not think this has been demonstrated) it might carry over to the widespread use of parallelism in poetry, which might be seen as a manifestation of syntactic priming, and thus a short-term creation and satisfaction of expectations. We also know that a word primes the selection of another word with which it rhymes, over a short distance (Hudson \& Tanenhaus 1985); this suggests that we formulate expectations about rhyme. Though these findings can be interpreted as indirect evidence that we formulate expectations about poetic form, they do not show that we build up expectations throughout a poem which are satisfied at its end. 
Smith's account of how our expectations are manipulated to produce closure can be examined by considering her discussion of the end of Blake's "Auguries of Innocence" (Smith 1968: 76-7) ${ }^{1}$.

We are led to believe a lie When we see not thro' the eye, Which was born in a night, to perish in a night, When the Soul slept in beams of light.

God appears, and God is Light,

To those poor souls who dwell in Night;

But does a Human Form display

To those who dwell in realms of Day

Here is Smith's account of how changes in poetic form lead to a sense of closure:

The metrically anomalous third line [127] and the bunching of rhymes in lines 3 to 6 [127-130] have the additional effect of disturbing the expectations previously established. The slight heightening of tension thus created is finally resolved in the final couplet, which, because it appears as a re-establishment of the metrical norm, has its independent closural effect strengthened.

Thus expectations are first established, then violated, then satisfied; this final satisfaction of expectations produces a sense of closure.

One expectation relates to metricality. After a four-line introduction, the text is almost entirely in regular iambic tetrameter, with most lines either seven or eight syllables long (both lengths are common in the poem). Towards the end of the poem, line 127 is significantly different, being the longest line and it is arguably unmetrical (it is 11 or 12 syllables depending on the pronunciation of 'perish'). So perhaps an expectation is established while reading lines 5-126 that lines are in iambic tetrameter. Then it is violated in line 127 by an unmetrical line. Then the original expectation of iambic tetrameter is re-established for the last five lines, and (for Smith) this produces a sense of closure.

A second expectation relates to the regularity of the rhythm relative to the iambic tetrameter metrical line. Smith describes the final couplet as a "reestablishment of the metrical norm". English iambic metres permit a great variety of rhythmic variation, which can include omitting the first syllable of the line. Both of the last two lines have eight syllables, and are rhythmically very regular. For Smith this means that they are closer to the norm than the preceding two lines. Hence we have an expectation which is violated near the end and then satisfied by the final two lines, a return to expectations which (for Smith) produces a sense of closure.

\footnotetext{
${ }^{1}$ Here as throughout, I use Smith's cited version of the text.
} 
A third expectation relates to the rhyme scheme. Except for the first four lines, the poem is all in couplets, but sometimes - as in lines 127-130 - two adjacent couplets have the same rhyme (Smith's "bunching of rhymes"). Smith treats this as a violation of an expectation that adjacent couplets have distinct rhymes, which is violated and then met in the final two lines which are a distinct single couplet. Hence this return to expectations produces a sense of closure.

Many of these claims about a return to a norm are open to challenge. Relating to the expectation of metricality, we might ask why a change to the metricality of a single line which is sixth from the end would contribute to a sense of closure. Or to rephrase: how far from the end can such a temporary change be while still having an effect on our experience of the ending? Next, relating to the second expectation, can we really say that the eight-syllable fully regular line is a norm in the text? Excluding the first four lines, 45 lines are seven syllables long, and 82 are eight syllables long. Does this mean that specifically eight-syllable lines are a norm? Furthermore, rhythmic regularity is difficult to determine as a norm, because degree of regularity is a choice in performance mainly depending on which grammatical words are optionally stressed; the penultimate line is only fully regular if we stress 'does'. More generally, because iambic metres tend to allow for rhythmic variation it is not clear that a rhythm which is fully periodic has any special status. Smith's third expectation, relating to rhyme, is more problematic still. This is because the "bunching of rhymes" in lines 127-30 (just before the final couplet) is also found in lines 55-58, 59-62, 63-66 and (just before the sequence quoted above) 121-124, so we might allow the bunching of lines to be a kind of secondary norm in the poem which we might characterise as shifting between single and paired couplets. Furthermore the specific rhyme on -ight is also quite common (in four couplets, and two 'double couplets' as here), which might make us wonder if the reader might formulate an expectation that this specific rhyme on-ight is particularly likely to appear; this is an expectation which is satisfied just before the end and then violated in the final couplet (which for Smith should be an anti-closural effect, contrary to her general account of this text). These are all questions about how norms are established, and what expectations a reader develops, all of which cast doubt on the detail of Smith's analysis.

\subsection{Tension}

The term 'tension' was introduced into literary criticism in an article by Allen Tate (1948) to describe a unity of vehicle (extension) and tenor (intension) in a metaphor, and in relation to the notion that the poem is read as a whole (with implications for Smith's closure). Another early use in aesthetics comes from Suanne Langer (1953: 372) who says that "the life of feeling is a stream of tensions and resolutions". The use of the term 'tension' in later literary criticism is intertwined with different meanings of the word 'tension' in psychoanalysis, psychology and aesthetics, and particularly the psychology of music. Its most common use in literary criticism is to describe a mismatch of rhythm and metre, and Smith uses it partly for this purpose. 
'Tension' can be illustrated by considering a metre such as iambic tetrameter, as used in Blake's poem. In an eight syllable line in this metre, the syllables which form the line must match a sequence of eight metrical positions with a periodic (repeating) structure involving a division into four pairs, where the second position in each pair is 'strong' or a 'head' of the pair (Fabb \& Halle 2008). The syllable carrying primary stress in a lexical word is normally required to match the strong/head position in the pair - that is, it should be an even-numbered syllable. In principle, the rhythmic pattern of eight syllables can be fully periodic, matching the pattern of the metre, but it need not be. Unstressed syllables and grammatical monosyllables are freely distributed (and the latter can be stressed or not stressed as the performer wishes). For example, Blake's iambic tetrameter line "When the Soul slept in beams of light" has a stressed syllable not in second but in third position, making the rhythm slightly irregular and aperiodic, even though this is a fully metrical line. These irregularities are conventionally described as 'metrical tension', and Smith uses the term in this way.

However, the term 'tension' is always problematic in literary criticism because it is ambiguous between a description of the form and a description of the experience of the form, as though cause and effect were merged. (It is worth noting that this merger of cause and effect is to some extent true of Smith's notion of 'closure', which seems in part to be a property of the text, partly a property of our experience of the text.)

Varying degrees or states of tension seem to be involved in all our experiences, and ... the most gratifying ones are those in which whatever tensions are created are also released. Or, to use another familiar set of terms, an experience is gratifying to the extent that those expectations that are aroused are also fulfilled. (Smith 1968: 3)

She suggests that the change from a loose rhythm to a strict rhythm is a change from greater to lesser tension which produces a psychological effect. However, though widely used, 'tension' is a word with no clear psychological meaning: Reber (1985: 765) in his Dictionary of Psychology calls it "ill-defined". Is there any evidence that lines with a mismatch between rhythm and metre produce a psychological effect of 'tension'? I do not think this has been tested for poetry, but similar questions have been asked about music. Fredrickson (1997) asked his listeners to squeeze hand-held spring-loaded tongs to indicate degrees of tension which they experienced while listening to a piece of music. Fredrickson found that different subjects did often indicate tension at the same parts of the musical piece, but he was unable to find a correlation between any formal feature of the music and the observed tension. This is another reason for being hesitant about using the term 'tension' to describe both a formal characteristic of the poetic line and the psychological response to it, as though the one was tied to the other. It should further make us cautious about attributing a specific psychological effect such as 'tension', as Smith does, to a shift from loose to strict form. 


\subsection{Gestalt theory, music and poetry}

Smith (1968: x, 33) acknowledges the influence of Gestalt theory, including Koffka (1935), E. H. Gombrich's 1960 Art and Illusion and Leonard B. Meyer's 1956 Emotion and Meaning in Music. Gestalt laws were first developed to account for visual perception, but - just as Meyer did for music - Smith argues that they can be extended to poetry. Gestalt theory includes the law of Prägnanz: "psychological organization will always be as 'good' as the prevailing conditions allow" (Smith 1968: 41), or in Meyer's (1956: 85) rephrasing: "the mind is constantly striving towards completeness and stability of shapes". Smith (1968: 36) takes a similar view that it is possible and desirable for the reader to "experience the structure of the work as, at once, both dynamic and whole". It is important for Smith that Gestalt theory applies to the text as a whole, and that our experience of closure is part of our knowledge of the text as a whole.

In a chapter on "completion and closure", Meyer argued that the hearer develops expectations about how the musical form will develop, including how the musical piece comes to an end, thereby achieving closure. These expectations are driven by Gestalt laws, but the specific expectations are dependent on the piece, the tradition, and other contextual aspects: "what represents completeness will vary from style to style and from piece to piece" (Meyer 1956: 128), a claim with which Smith agrees (1968: 31). An example of musical closure can be found in classical sonata form with a sequence ending in the fall from the dominant to the tonic, a descent of a fifth. This is a generic description of closure; in any specific piece the actual tonic (e.g., C, or F sharp) will have been determined by the preceding form of the particular piece of music, and to some extent these specific expectations about how the piece ends may be formulated already on hearing the beginning of the piece. The expectations which lead to closure thus depend in part on knowledge of the musical conventions and genre, and in part on the preceding form of the particular piece.

Can Gestalt principles be applied to poetry, and if so, do they support Smith's theory? The application of Gestalt theory to poetry has been pioneered by Reuven Tsur. For example, Tsur (2015: 37) argues that lineation and syntactic constituency can "reinforce each other's Gestalt". Tsur et al. (1991) apply Gestalt theory to the shape of the 'Rubaiyat'-style stanza with an $A A B A$ rhyme scheme. They predicted that "on the prosodic level, the rhyme-scheme of the stanza is felt to close the $A A B A$ version firmly, with a 'click'; this effect is reinforced by the closing-aspect of the 'closural allusion' on the thematic level." (Tsur et al. 1991: 498). However their experimental results show that $A A B A$ and alternative $A A A A$ rhyme schemes lead to similar judgements that the stanza is 'closed'. The authors note that "[w]e have thus far relied primarily on the analysis of the 'closural allusion' in accounting for our results" (Tsur et al. 1991: 499); that is, the judgements of closure may be coming just from the meaning and it is not clear that the form plays a role in producing closure. This is evidence against Smith's approach. 
It is important to note that Tsur attempts to apply Gestalt theory and associated notions of closure to small parts of a text such as a line, or a stanza. Similarly Tillmann and Dowling (2007: 637) say that poetic closure is a characteristic of small sections such as couplets or lines, e.g., "In poetry, recurring rhymes contribute to the structuring of the flow of the phrases, providing closure in the form of a predictable point of stability at the end of a phrase." In neither case is the property of closure claimed to hold of a text as a whole, as Smith argues. Like the evidence cited earlier from priming (relating to parallelism and rhyme), the evidence from Gestalt theory suggests that formal anticipations (and the expectation of closure) may hold only over short sections of a text, not sustained over long stretches or over the text as a whole, as Smith requires.

A further argument against a Gestalt account of poetic closure will come from my proposal, to be spelled out in the next section, that at the end of a poem there is significantly increased processing effort which is demanded by a "terminal modification of a formal principle" (Smith's phrase). Gestalt theorists have argued that figural goodness is dependent on decreased amounts of information, and so should involve lower processing effort (Reber et al. 2004: 368). If I am right to suggest that at the endings of some poems there is increased information leading to increased processing effort then the endings of many poems with closural effects should not enable the formation of good Gestalts.

\section{An alternative account based on relevance theory}

\subsection{Closure as a cognitive effect}

I now suggest an alternative to Smith's account, based on relevance theory (Sperber \& Wilson 1995). I assume that the writing of a poem is a communicative act in the sense that its author's goal is to produce cognitive effects in its reader (though not in the crude sense that it aims to communicate a message). As a communicative act it obeys the principle of relevance (Sperber \& Wilson 1995: 58).

The principle of relevance: Every act of ostensive communication communicates the presumption of its own optimal relevance

\section{Presumption of optimal relevance:}

(a) the set of assumptions $\{l\}$ which the communicator intends to make manifest to the addressee is relevant enough to make it worth the addressee's while to process the ostensive stimulus.

(b) the ostensive stimulus is the most relevant one the communicator could have used to communicate $\{l\}$.

The crucial aspect of the principle of relevance for our purposes is that "an utterance is optimally relevant to the hearer just in case it is relevant enough to be worth the hearer's processing effort" (van der Henst \& Sperber 2004: 144). 
Poetic form demands additional processing effort from its reader, and various cognitive effects might be produced as a result (Pilkington 2000, Fabb 2002, MacMahon 2007, Clark 2014, Chapman \& Clark 2014). One kind of cognitive effect is the generation of a thought about the poem, that the poem has a particular kind of poetic form. Such a thought would be relevant in the context of judging the skill of the poet. A second kind of cognitive effect might be directly associated with the specific text. For example, the recognition of a rhyme between two words can draw attention to a relation of meaning between them (as in the common pairing of 'womb' and 'tomb' in seventeenth century poetry). A third kind of cognitive effect involves a formal change in a text which has no specific meaning, but because it puts the reader to extra processing effort, therefore encourages the reader to seek out a meaning which would otherwise not be sought. Sperber \& Wilson (1995: 219) use the example of a repeated word or phrase, which adds nothing to the logical form of the sentence, but puts the reader to greater processing effort because it requires the processing of extra words, and so encourages the reader to search for cognitive effects such as extra implications which justify the effort of processing the repetition. Kind (2016) argues similarly that Elizabeth Bowen makes the linguistic form of her prose difficult in order to create a general increase in processing effort which has indirect but non-coded consequences for the reader's aesthetic experience. The forms of the literary text in this case do not encode the cognitive effects which they cause the reader to discover. Instead of a direct causal relation between form and cognitive effect, relevance theory encourages the reader to find a cognitive effect which is indirectly caused by the form in context, mediated by processing effort. This is contrary to the approach taken in many applications of rhetoric and stylistics, including Smith's approach.

In this article, I focus on a particular kind of cognitive effect, which is the formulation of the thought 'this poem has closure'. Smith argues that the ends of poems involve the "terminal modification of a formal principle" and this produces a sense of closure. I argue instead that these changes in poetic form require the reader to increase processing effort. However, the formal changes do not in themselves encode or otherwise imply specific cognitive effects which might justify the processing effort. Thus the reader must create a thought about the text which is sufficiently relevant to justify the effort demanded. One such relevant thought is that 'the poem has closure'. Other thoughts might be formulated instead, if they are also highly relevant, including thoughts such as 'this poem lacks closure' or 'this poem has anti-closure' or some other thought. Which of these thoughts is chosen is likely to depend on other factors, most of which are independent of the poetic forms but may relate to the meaning of the text, along with expectations about the type of poem, about how poems should end, about poetry in general, and so on. Where the poem has a coherent meaning (describing a single event, for example), then the coherence of the meaning at the end reinforces the thought that 'the poem has closure'. We might also formulate a thought 'this poem has closure' because we expect poems to have closure. The next part of my argument is that the term 'closure' is not fully understandable; I explain this now. 
Smith says that "the sense of ultimate composure we apparently value in our experience of a work of art is variously referred to as stability, resolution or equilibrium" and that closure "reinforces the feeling of finality, completion, and composure which we value in all works of art" (Smith 1968: 34, 36). Note the periphrastic way in which closure is here explained, suggesting that the sense of closure cannot be fully specified, but only hinted at by appealing to our understanding of the unstated core of the experience. I suggest that this is because 'closure' is a term which cannot be fully understood, which is why the sense of closure cannot be directly expressed in Smith's descriptions.

Thoughts and sets of thoughts need not be fully specified and can include terms whose meaning is not fully understood by the person thinking them. We can have thoughts which we do not fully understand, often because they include terms which we do not fully understand. Following Sperber (1975) we can say that these are 'schematic thoughts', by which he means thoughts whose content is not fully specified, whose associated propositions are not capable of being assigned a truth value (see also Recanati 1997 for an analogous view). Sperber notes that schematic thoughts can be held as strong beliefs, and that they are liable to spread throughout a culture. These thoughts are the basis of cultural symbolism, precisely because of their lack of full specification. Smith (1968: 152) suggests that the sense of closure is often associated with an impression of truth or validity, "a quality that leaves [the reader] with the feeling that what has just been said has the 'conclusiveness', the settled finality, of apparently self-evident truth." Exactly the same can be said of the culturally and religiously fundamental schematic thoughts described by Sperber: there may be a tendency to attach a deep truth to those schematic thoughts which cannot be paraphrased. The thought that 'this poem has closure' is likely to lead to further exegeses, speculations and explanations, thus generating an increased range of cognitive effects. The thought 'this poem has closure' gains its relevance in part because it is able to generate a range of other thoughts about the poem, about poetry, about the meanings of the poem, and so on. The terms 'anticlosure' and 'non-closure' are similarly obscure in their meaning, and thoughts which include these terms are thoughts with a potential for further speculation.

Some support for this interpretation of poetic closure comes from I. A. Richards's (1926) Principles of Literary Criticism, which is a foundational attempt to understand literary experience from a psychological perspective (he mentions but makes little use of Gestalt theory). He uses the term 'closure' to describe a psychological effect which he also calls 'poise' or 'completeness' (Richards 1926: 107). He concludes his book by discussing feelings of insight or visionary moments, which he considers to be a type of 'objectless belief', something which appears to be knowledge but is in fact just an arrangement of the feelings, produced for example by a successful work of art. There is some similarity between Richards's objectless belief and Sperber's schematic thought, because both feel as though they have significant contents which however cannot be expressed. Richards (1926: 283) says that this objectless belief is like "the conclusive answering of a question", which hints at the possibility that he treats the experience of closure as an objectless belief. 


\subsection{Processing effort}

In this section I discuss how the poetic form or the linguistic form of a poem might influence the reader's processing effort, a key notion in relevance theory because when a poem asks a reader to expend processing effort, the poem guarantees that relevant cognitive effects will follow. In reading poetry, effort is expended on processing linguistic form, and on processing poetic form; in addition, poetic form can have an effect on the processing of linguistic form. It is worth noting that context can significantly affect the ways in which form affects processing effort. Gibbs \& Tendahl (2006: 399) show this in their discussion of metaphor, where they demonstrate that context can determine the speed of processing of an utterance, and can determine whether metaphors express more or fewer meanings, and stronger or weaker explicatures and implicatures. Note also that processing effort can lead to cognitive effects without the subject being conscious of the processing effort (van der Henst \& Sperber 2004: 142). The search for cognitive effects is triggered by the expenditure of effort. This means that the reader need not be conscious that she is put to extra processing effort at the end of the text, and need not be conscious of the formal changes. This fits with the fact that neither formal salience nor markedness is a prerequisite for the sense of closure, which I claim to be a cognitive effect.

The processing of linguistic form includes the categorization of perceived inputs (i.e., identifying sounds and words), the building of structure (e.g., syntactic, semantic and prosodic structure), and the production of new representations such as inferences. Along with categorization, structure-building and inference, processing effort is required to hold linguistic material in working memory and to move material between working memory and long term memory (on working memory see Cowan 2012 or Baddeley 2012). See also Schmidt and Seger's (2009) suggestion that greater processing difficulty involves greater right cerebral hemisphere involvement. Aspects of the text or its interpretation which might influence the amount of effort required to process the text include the following.

(i) Perception of the text can be easier or more difficult which will influence processing effort (e.g., in a noisier environment, Schmidt \& Seger 2009: 377).

(ii) Different kinds of syntactic structure may require different amounts of processing effort (e.g., complexity of embedding, relation between grammatical and thematic structure, etc.).

(iii) A text which has more words in it requires more processing effort (Sperber \& Noveck 2004: 6).

(iv) Some words may require more processing effort than others to identify perhaps because they are less familiar. Carston (2005: 275) says that more frequent words cost the hearer less effort to match words from the mental lexicon to the heard or read input (in order to recognize the 
word); Schmidt \& Seger (2009: 377) suggest that unusual verbs and unrelated words cause greater processing effort.

(v) Interpretation may require the construction of bridging inferences which can differ in how easy they are to construct or retrieve (Wilson \& Matsui 2012: 205).

(vi) Some thoughts are easier to process than others, if those thoughts are taken as premises in further deductions. Thus a rounded time number such as $4.30 \mathrm{pm}$ is easier to process than unrounded 4.28pm (van der Henst \& Sperber 2004: 165).

(vii) The choice of a discourse marker can make information more or less easy to process (Blakemore 2004: 36).

(viii) Representation of a sequence of events is easier to process if the sentences are ordered in event sequence (Carston 2005: 275).

(ix) Sometimes, processing effort is expended in a first stage in order to reduce processing effort at a later stage. Van der Henst \& Sperber (2004) discuss a case in which effort is expended on deducing a conclusion from two premises but because the conclusion is simpler than the pair of premises, the deduction reduces subsequent processing effort.

(x) A sentence with greater novelty demands higher processing effort (Bohrn, Altmann, Lubrich, Menninghaus \& Jacobs 2013: 4).

I have looked at ways in which effort is expended in the processing of language. Now I turn to poetic form, which influences processing effort in two ways. First, identifying the poetic form requires processing effort (even if it is unconsciously identified). Second, the presence of poetic form might influence the processing effort required for linguistic form.

Poetic form in English poetry includes the regular added forms of metre and rhyme, and forms which may be added occasionally such as alliteration and parallelism (in literatures other than English these can also be regular). These forms are partially dependent on the division of the text into sections such as lines, couplets and stanzas. Fabb (2015) argues that the various added forms of poetry are processed in working memory over sections of text such as lines which are held as wholes in working memory. Poetic form demands processing effort in three ways.

First, if the reader is aware that the poem is in a metre, or has rhyme, or some other poetic form, then she will have expended effort to recognize and categorize that form. Literary linguistic research suggests that quite complex operations are involved. Miall (1995: 283) shows this experimentally, demonstrating that the more foregrounded a passage (e.g., by increased or changed literary form), the greater the processing requirements placed on the 
reader. He shows that readers read such passages more slowly, suggesting that they are putting more processing effort (taking more time) into the text at this point. I assume that poetic form can also be processed unconsciously or below conscious awareness (just as linguistic form can be processed unconsciously). There is a further interesting possibility: a form might be uniformly present throughout, but the reader at a certain point increases the processing effort put into identifying it, perhaps because the form becomes more salient. In summary, if a new form appears, then processing effort is increased.

Second, poetic forms can vary in their regularity. A line's rhythm can be closer to or further from the underlying metrical pattern, and two words can rhyme more or less strictly (e.g., final consonants may be identical or just similar). When a form is less regular it may require more processing effort to identify it. Thus Halle and Keyser (1971: 176) measure metrical complexity by "the degree of difficulty that a reader will experience in discerning the abstract metrical pattern in a line". For our purposes, this suggests that if a form becomes less regular, then processing effort will be increased.

Finally, Tse et al. (2004) note that an unexpected event may increase the rate of information processing brought to bear on the event. If we interpret this to suggest that any change is unexpected, then it suggests that any change in a poetic form might lead to an increase in processing effort. This includes not only a new form or a loosening of form but importantly also includes a change from loose to strict form. Thus a poem which ends with a penultimate shift from strict to loose form will increase processing effort, and then the final shift from loose to strict form will further increase processing effort, just because it is a change. One possible challenge to this view is that a shift to final strictness may not be an unexpected event if we start out with expectations that poems end strictly. This means that a shift from loose to strict should be expected which would then reduce processing effort. However, an answer to this might come from a distinction between expectations of the generic text-type as opposed to expectations of the specific text-token which we are reading at the moment. This is analogous to the distinction between schematic (type-based) expectations and dynamic (token-based) expectations of musical form as discussed by Bharucha (1994) and Huron (2006: 225-6) (see also Gerrig 1993: 172, who draws an analogy between these ideas and narrative suspense). It may be that we have an expectation of a strict ending based on our expectations of the type of text. However, at the same time our expectations of a particular text might be dynamically developing, and may be guided by an expectation that any current state will continue, such that any change is a surprise; hence any shift including a shift from loose to strict form will be unexpected and so should raise processing effort.

These are ways in which the processing of poetic form in itself demands effort. All three type of change to poetic form are identified by Smith as characteristic of the ends of poems which she identifies as having a closural effect. 
Now I turn to ways in which the presence of poetic form can affect the processing of language, making the language either harder or easier to process. Thus the requirement to fit the stressed syllables of words into the pattern required by a metre, or the need to construct a rhyme, might require the words to be reordered in a way which makes constructing their syntactic representation more difficult. Similarly, a match or mismatch between poetic sections (line, quatrain, stanza) and linguistic constituents (syntactic or prosodic) might affect how much effort is required to process the linguistic constituents. An enjambment where a phrase is split across a line boundary may demand more processing effort to identify that phrase as a single constituent. A further consideration is that when a poetic form such as metre or rhyme is very regular, linguistic processing effort should be eased; for example if we know that a word at the end of a line must rhyme with a previous word, we need only search in a restricted area of the mental lexicon to find that word and match it with the sensory input. This easing of processing effort, also known as in the psychological literature as 'fluency of processing', has been experimentally demonstrated as an effect on the reader of regular poetic form (Obermeier et al. 2016, Fabb 2015: 188-91). These considerations about the influence of poetic form on the processing of linguistic form all add to the complexity of claims around how a text might influence its reader's search for contextual effects, by increasing or decreasing processing effort. Note that some of these effects on the processing of language will ensue even if the reader does not process the form itself, because the difficulties arise at the level of composition: it is the composition of a metrical line which affects the difficulty of its syntax, not the recognition of that line as metrical by a hearer. On the other hand, other forms have an effect on processing only if they themselves are processed (even if unconsciously): rhyme can only affect lexical selection space if rhyme is processed and so here an additional effort (the processing of rhyme) is required to save effort elsewhere (lexical selection).

Thus we see that at a poem's end, processing effort can be increased by changes in the linguistic form and changes in the poetic form, including ways in which the linguistic form is made more difficult to process by changes in the poetic form.

\subsection{Smith's examples reanalysed in terms of increased processing effort}

In this section, I examine the endings of some of the poems which Smith quotes and I show both that the formal changes always increase the reader's processing effort, and that they fail to provide consistent evidence for Smith's association of specific types of change with closure.

(i) Thomas Herrick, "The Argument of his Book" (discussed in Smith 1968: 108)

Herrick's fourteen-line poem is in couplets; these are the last four lines: 
I write of Groves, of Twilights, and I sing

The court of Mab, and of the Fairie-King.

I write of Hell; I sing (and ever shall)

Of Heaven, and hope to have it after all.

Smith claims that "the loose syntax and flowing rhythm of the earlier lines are abruptly tightened and arrested at the beginning of line 13: 'I write of Hell'" and that this produces a sense of closure. Smith also says that the introduction of 'hope' brings the only new verb into the poem other than 'write' and 'sing' and that this introduction of a new form at the end 'strengthens closure'. We might counter that both formal changes are accompanied by a loosening of form, by the use of the poem's only parenthetical (a loosening of syntactic structure) in line 13, and by the move from a strict two-verb pattern throughout the poem to a final three-verb pattern. Thus it is not always clear whether any particular formal change should be interpreted as a tightening or loosening of form. We can avoid this problem by just characterising the end of the poem as involving various formal changes, all of which increase processing effort, in this case linguistic processing effort. The addition of 'hope' increases processing effort because it is the first time a new verb has been introduced into a poem which has previously used only 'write' and 'sing'. The parenthetical increases processing effort because it interrupts the processing of the syntactic structure of its host sentence.

(ii) Andrew Marvell, "The Nymph complaining for the Death of her Fawn" (discussed in Smith 1968: 71)

Marvell's poem is in twelve couplets, of which the final couplet is this:

There is not such another in

The World, to offer for their Sin.

Smith suggests that the final couplet strengthens closure. This is because three of the preceding couplets have had syntactic enjambments from one couplet into the next, but this couplet is a coherent whole, and this strict matching of syntax to couplet causes closure. However, we might equally note that the couplet-internal enjambment between the final preposition of the penultimate line to the initial noun phrase of the last line is the loosest enjambment in the poem (for example because this is not a possible prosodic phrase boundary); thus at the level of the line, the final two lines have the loosest matching of syntax to line. The ending is strict if we look at the final couplet but loose if we look at the final two lines. I suggest that the final couplet demands increased processing effort which is required in order to make sense of the syntactic structure when it is so radically interrupted by a line boundary made salient by rhyme. Furthermore, the word 'in' is not normally stressed when it is followed by a noun phrase, but here it must be in order to allow it to rhyme with 'sin'; this additional demand also increases processing effort.

(iii) Walt Whitman "Vigil strange I kept on the field one night" (discussed in Smith 1968: 93) 
Smith quotes the end of Whitman's poem, of which these are the two final lines:

I rose from the chill ground and folded my soldier well in his blanket, And buried him where he fell.

She says that the use of "the abruptly shorter terminal line" is a formal strengthening of closure because it is the "terminal modification of a formal principle" which inherently produces closure. But it is not clear why: we might equally say that a final change is an opening up of a poem, not a closing of it. Hayes \& MacEachern's (1998) long-last principle says that "In a sequence of groups of unequal length, the longest member should go last", meaning that a final shortening should be anomalous. Similarly, Tsur (2013: 13) suggests that "in a series of parallel items, other things being equal, 'longest comes last' is the well-formed order"; thus this type of change to a short line should be ill-formed, producing a bad Gestalt and thereby presumably preventing closure. The relationship between form and closure is thus not determinate. I suggest instead that we treat final formal changes only as producing increased processing effort. Smith also says that closure is strengthened by assonance, alliteration and rhyme (well/fell) in the last two lines; again we would say that the need to identify these forms increases processing effort.

(iv) Emily Dickinson, "Finding is the first Act" (discussed in Smith 1968: 111)

Dickinson's poem is in two four-line stanzas; this is the final stanza:

Fourth, no Discovery -

Fifth, no Crew -

Finally, no Golden Fleece -

Jason - sham - too.

This is a poem which Smith claims achieves closure by its sequential content which reaches a terminal point (i.e., thematic closure). However, the final line is also syntactically the loosest, consisting of three words separated by hyphens (which themselves appear only in the second stanza). The poem thus becomes increasingly loose syntactically, which goes against Smith's claim that increased strictness correlates with closure. However, if we look at processing effort we can see that the poem requires increased processing effort towards the end, because the loose syntax makes the coded meaning harder to determine.

(v) Matthew Arnold, "East London" (discussed in Smith 1968: 124)

This is the last line of Arnold's sonnet:

Thou mak'st the heaven thou hop'st indeed thy home.

This is another poem in which Smith identifies only thematic closure. The triple alliteration in this line is an increase in non-structural form which elsewhere Smith treats as a closural device (and in our terms increases processing effort). However, linguistically the line presents some challenges both in its relation to 
the metre and in its syntax. It requires contractions in 'mak'st', and 'hop'st' (as well as the conventional contraction of 'heaven') to bring what might be a twelve or thirteen syllable line into the ten positions of the metre. And it contains a reduced relative with a missing preposition ('thou hop'st' for). This ought to be a disruption or looseness at the end of the poem, producing openness not closure. The last line thus mixes what Smith considers elsewhere to be a closure device with what looks as though it should be an anti-closure device. I suggest that we remove this contradiction by saying instead that the forms of the line just increase processing effort in two ways.

(vi) George Herbert, "Redemption" (discussed in Smith 1968: 125)

Herbert's sonnet has the rhyme pattern abab-cdcd-effe-gg, and these are the last three lines:
At length I heard a ragged noise and mirth
Of theeves and murderers: there I him espied,
Who straight Your suit is granted, said, \& died.

This is another poem for which Smith only identifies thematic closure. But formally the end of the poem ought to have the opposite effect, because the couplet is not an isolated unit - the third quatrain enjambs into it - and the last line is syntactically disrupted (the complement of 'said' precedes it, rather than follows). Again, these formal disruptions increase processing effort, by virtue of the need to process the syntactic structure when it is disrupted by the lineation.

(vii) John Keats, "Ode to a Nightingale" (discussed in Smith 1968: 127)

Keats's ode is in iambic lines of variable lengths; these are the last two lines of the poem which Smith suggests "presents no special closural problem" (i.e., has closure).

Was it a vision, or a waking dream?

Fled is that music: - Do I wake or sleep?

Smith finds the closure of the poem in its thematic development, but ignores the many ways in which the forms are of a kind which otherwise she would say are 'non-closural'. The last two lines present the only questions in the poem (and they are unanswered), which surely does not express closure. Further, both lines begin with trochaic inversions, where the iambic line begins stressedunstressed-unstressed-stressed. Smith elsewhere sees trochaic inversion as a creation of metrical tension which should be resolved (Smith 1968: 44), but here it is not. And the final line is interrupted syntactically in the middle, again a type of disruption which Smith treats elsewhere as lacking closure. Form thus does not directly code closure as Smith predicts; however, in our terms it is clear that the end of the text demands increased processing effort (which can indirectly lead to the conclusion that the poem has closure). 
(viii) John Milton, “Lycidas” (discussed in Smith 1968: 129 192-4)

Milton's poem is generally in unrhymed iambic pentameter, with a rhyme scheme emerging at the end. This is the final couplet:

At last he rose, and twitch't his Mantle blue:

Tomorrow to fresh Woods, and Pastures new.

Smith focuses on the poem's thematic closure, and if we apply Smith's approach to the final forms, we might say that the final rhyme is a closing device, both because it is a new form, and because it ends on a couplet. On the other hand, the final sentence lacks a verb, which is a disruption of the syntax which should work against closure. The poem thus appears to mix closural and anti-closural forms (from Smith's perspective). I suggest however that in all cases the formal changes increase processing effort; they are neither closural nor anti-closural in themselves, but just promise cognitive effects which can be realized as the thought that the text has closure (which is formulated on the basis of the meaning not the form of the text).

I have selected various poems which Smith claims have closure but which have forms which become looser rather than stricter at the end. Smith acknowledges that poems may have thematic closure without support from formal closure (even with formal anti-closure). She says that these are cases of "hidden closure" (Smith 1968: 244), where the closure based on meaning is hidden by non-closural forms. This weakens her argument that form is the cause of closure.

\subsection{Processing effort and the production of closure}

Smith argues that "one of the most common and substantial sources of closural effects in poetry is the terminal modification of a formal principle" (Smith 1968: 92). I agree, and have suggested that the terminal modifications of a formal principle always produce an increase in processing effort, that this increase in processing effort can encourage the formulation of the thought that the poem has closure, and that the formulation of this thought is what Smith calls "the sense of closure". I have argued that certain types of formal change inherently demand greater processing effort. Forms change throughout a poem, and this has consequences for processing effort. Where several forms change at the same time, as they characteristically do at the end of the poem, the combined effect will be greater. It is this significantly increased processing effort which encourages the search for a significantly relevant thought such as 'this poem has closure'.

Closure is associated with the ends of poems, and there might be reasons why at the end of a poem, increased processing effort is demanded. The need to process the linguistic form of the current text disappears once the poem is finished. Perhaps the reader's newly released processing capacity can be redirected to the parts of the text which remain in memory. For example, 
working memory may retain the most recently read one or two lines in the episodic buffer (Fabb 2015), and they could be held there after finishing the poem, hence holding the last one or two lines longer than previous lines. This would mean that increased processing effort would always be devoted to the end of a poem, irrespective of any other formal or thematic aspect of the end. More generally, perhaps the reader devotes increased processing effort to reflecting back on it as a whole, its meaning, value, and so on.

In summary, I suggest that the sequence of psychological events is as follows. At the end of the text, the reader is faced with significant additional processing effort as a result of multiple changes in poetic form, and this requires the reader to search for adequate cognitive effects to justify the processing effort. A satisfactory solution is to formulate a schematic thought that 'this poem has closure' but where the term 'closure' itself lacks a clear meaning. Such an interpretation can be produced in a context where meaning and other aspects of the poem suggest that the poem reaches closure. Because closure is valued in certain cultural contexts, and the thought that there is closure is 'gratifying' (Smith's term), the formulation of the sense of closure justifies the processing effort put into deriving it, thus satisfying the principle of relevance. Note furthermore that because the thought that 'this poem has closure' is a schematic thought, like other schematic thoughts it is open to further inference and speculation; thus the formulation of 'a sense of closure' can be the beginning of a set of thoughts about the text, rather than its conclusion. Sperber (1975) argues that this is exactly how schematic thoughts gain their power.

If the 'sense of closure' is actually a schematic thought that 'this poem has closure' but with the meaning of closure somewhat undefined, then it should have some of the properties of a schematic thought, which paradoxically include its being open to interpretation (rather than closed). This means that there is a core of non-closure within the 'sense of closure', which may be part of its aesthetic effect. It explains why the sense of closure cannot be paraphrased, and why texts with closure nevertheless can be read again with new pleasures. We can also add to an explanation of why these texts with 'a sense of closure' are pleasurable, by appealing to evidence of the pleasures of uncertainty. Wilson et al. (2005) show that when a sequence of events is known to have a happy outcome, then there is pleasure in the uncertainty about what exactly that outcome will be. Their 'pleasure of uncertainty' hypothesis is that "the pleasure people derived from the events would last longer in the conditions in which people had difficulty making sense of them" (Wilson et al. 2005: 7). Similarly, Armstrong and Detweiler-Bedell (2008: 321) say that affective arousal in response to novelty is increased if closure is not achieved. In our experience of an aesthetic object, uncertainty is always pleasurable because any outcome can be predicted to be least harmless, and usually pleasurable. If even the thought that 'this text has closure' has a core of uncertainty coming from the uncertain notion of 'closure' at its core, then even a 'closed' text will continue to offer the pleasures of uncertainty.

The account I have given of poetic closure is different in several fundamental ways from Smith's account. However, aspects of my argument are already 
present in Smith's book. Her claim that an emergent (hence unexpected) form at the end of a text produces closure seems correct but is hard to reconcile with her view that closure relates to the satisfaction of expectations. On the other hand, it is entirely compatible with my view that the end of the text demands increased processing effort (which indirectly can lead to closure). Further, when discussing texts which have closure in meaning but not form, she expresses concern that "the notion of formal 'integrity' in this sense may indeed be chimerical" (Smith 1968: 28). I have made the same claim. She agrees with Meyer $(1956: 85,128)$ that we do not have an innate sense of closure, but that we learn types of closure; Smith also suggests that the experience of closure is context-dependent, and can change according to genre, or historically (Smith 1968: 31 ). This fits with the idea that closure is not a type of experience but instead is the content of an inferred thought, derived in part because of its context. She also says that "poetic structure is, in a sense, an inference which we draw from the evidence of a series of events", and my proposal is fundamentally the same: we make inferences from form and about form (a position defended in Fabb 2002).

\section{Conclusion}

Smith describes a distinctive kind of experience as caused by both formal and thematic elements in a poem, but her explanation of formal causation faces theoretical problems and is not supported by the poems she cites as evidence. Smith's account of specific forms as having a direct causal relation to closure cannot be sustained, but we can retain a role for poetic form by focusing on her suggestion that terminal modification of form leads to closure. I suggest that this terminal modification has the result of increasing processing effort. Increased processing effort can encourage the reader to search for cognitive effects, and a relevant effect is the formulation of the belief that 'this poem has closure'.

\section{Acknowledgements}

Thanks to the two reviewers, to Billy Clark, Julia Kind, Hannah Sullivan, Anja Müller-Wood and Christoph Unger. This article is a development of a talk given at the conference, Research Agendas in Literary Linguistics, 15-17 April 2015, Johannes Gutenberg-Universität Mainz, and I thank the audience for comments. The research for this article was funded by the Leverhulme Trust as part of a three-year Major Research Fellowship titled 'Epiphanies in literature: a psychological and literary linguistic account'.

\section{References}

Armstrong, Thomas \& Detweiler-Bedell, Brian (2008). Beauty as an Emotion. The Exhilarating Prospect of Mastering a Challenging World, Review of General Psychology, 12(4), 305-329.

Baddeley, Alan (2012). Working Memory. Theories, Models, and Controversies, Annual Review of Psychology, 63, 1-29. 
Barnes, Ralph \& Jones, Mari Riess (2000). Expectancy, Attention, and Time, Cognitive Psychology, 41(3), 254-311.

Bharucha, Jamshed J. (1994). Tonality and Expectation. Musical Perceptions, eds. Rita Aiello \& John Sloboda. New York: Oxford University Press, 213-239.

Blakemore, Diane (2004). Discourse Markers. The Handbook of Pragmatics, eds. L. Horn \& G. Ward. Oxford: Blackwell, 221-240.

Bohrn, Isabel C., Altmann, Ulrike, Lubrich, Oliver, Menninghaus, Winfried \& Jacobs, Arthur M. (2013). When We Like What We Know. A Parametric fMRI Analysis of Beauty and Familiarity, Brain and Language, 124(1), 1-8.

Carston, Robyn (2005). A note on Pragmatic Principles of Least Effort, UCL Working Papers in Linguistics, 17, 271-278.

Clark, Billy (2014). Stylistics and Relevance Theory. Routledge Handbook of Stylistics, ed. Michael Burke. London: Routledge, 155-174.

Chapman, Siobhan and Billy Clark (2014). Pragmatic Literary Stylistics. Basingstoke: Palgrave MacMillan.

Cowan, Nelson, Rouder, Jeffrey N., Blume, Christopher L. \& Saults, J. Scott (2012). Models of Verbal Working Memory Capacity. What Does It Take to Make Them Work? Psychological Review, 119(3), 480-499.

Fabb, Nigel (2002). Language and Literary Structure. The Linguistic Analysis of Form in Verse and Narrative. Cambridge: Cambridge University Press.

--- (2015). What is Poetry? Language and Memory in the Poems of the World. Cambridge: Cambridge University Press.

Fabb, Nigel \& Halle, Morris (2008). Meter in Poetry. A New Theory. Cambridge: Cambridge University Press.

Fredrickson, William E. (1997). Elementary, Middle, and High School Student Perceptions of Tension in Music, Journal of Research in Music Education, 45, 626635.

Gerrig, R. J. (1993). Experiencing Narrative Worlds. On the Psychological Activities of Reading. New Haven: Yale University Press.

Gibbs Jr., Raymond W. \& Tendahl, Markus (2006). Cognitive Effort and Effects in Metaphor Comprehension. Relevance Theory and Psycholinguistics, Mind and Language, 21, 379-403.

Gombrich, E. H. (1960). Art and Illusion. A Study in the Psychology of Pictorial Representation. Oxford: Phaidon Press.

Halle, Morris \& Keyser, Samuel Jay (1971). English Stress. Its Form, its Growth, and its Role in Verse. New York: Harper and Row.

Hayes, Bruce P. \& MacEachern, Margaret (1998). Quatrain Form in English Folk Verse, Language, 74, 473-507.

Hudson, Susan B. \& Tanenhaus, Michael K. (1985). Phonological Code Activation During Listening, Journal of Psycholinguistic Research, 14(6), 557-567.

Huron, David (2006). Sweet Anticipation. Music and the Psychology of Expectation. Cambridge, MA: MIT Press. 
Kind, Julia (2016). Elizabeth Bowen's 'Narrative Language at White Heat'. A LiteraryLinguistic Perspective. Unpublished PhD thesis, Johannes Gutenberg-Universität Mainz.

Koffka, Kurt (1935). Principles of Gestalt Psychology. London: Lund Humphries.

Langer, Suzanne K. (1953). Feeling and Form. A Theory of Art. London: Routledge and Kegan Paul.

MacMahon, Barbara (2007). The Effects of Sound Patterning in Poetry. A Cognitive Pragmatic Perspective, Journal of Literary Semantics, 36(2), 103-120.

Meyer, L. B. (1956). Emotion and Meaning in Music. Chicago: University of Chicago Press.

Miall, David S. (1995). Anticipation and Feeling in Literary Response. A Neuropsychological Perspective, Poetics, 23, 275-298.

Obermeier, Christian, Kotz, Sonja, Jessen, Sarah, Raettig, Tim, Koppenfels, Martin \& Menninghaus, Winfried (2016). Aesthetic Appreciation of Poetry Correlates with Ease of Processing in Event-Related Potentials, Cognitive, Affective, \& Behavioral Neuroscience, 16(2), 362-373.

Pilkington, Adrian (2000). Poetic Effects. A Relevance Theory Perspective. Amsterdam: John Benjamins.

Reber, Arthur S. (1985). The Penguin Dictionary of Psychology. London: Penguin.

Reber, Rolf, Schwarz, Norbert \& Winkielman, Piotr (2004). Processing Fluency and Aesthetic Pleasure. Is Beauty in the Perceiver's Processing Experience? Personality and Social Psychology Review, 8, 364-382.

Recanati, François (1997). Can We Believe What We Do Not Understand? Mind and Language, 12, 84-100.

Richards, I. A. (1926). Practical Criticism. 2nd edition. London: Routledge \& Kegan Paul.

Sakita, Tomoko I. (2006). Parallelism in Conversation. Resonance, Schematization, and Extension from the Perspective of Dialogic Syntax and Cognitive Linguistics, Pragmatics \& Cognition, 14(3), 467-500.

Schmidt, Gwenda L. \& Seger, Carol A. (2009). Neural Correlates of Metaphor Processing. The Roles of Figurativeness, Familiarity and Difficulty, Brain and Cognition, 71(3), 375-386.

Smith, Barbara Herrnstein (1968). Poetic Closure. A Study of How Poems End. Chicago: University of Chicago Press.

Sperber, Dan (1975). Rethinking Symbolism. Cambridge: Cambridge University Press.

Sperber, Dan \& Noveck, Ira A. (2004). Introduction. Experimental Pragmatics, eds. Ira A Noveck \& Dan Sperber. New York: Palgrave Macmillan, 1-22.

Sperber, Dan \& Wilson, Deirdre (1995). Relevance. Communication and Cognition (2nd ed.). Oxford: Blackwell.

Sturt, Patrick, Keller, Frank \& Dubey, Amit (2010). Syntactic Priming in Comprehension. Parallelism Effects with and without Coordination, Journal of Memory and Language, 62 (4), 333-351. 
Tate, Allen (1948). On the Limits of Poetry. Selected Essays 1928-1948. New York: Swallow Press.

Tillmann, Barbara \& Dowling, W. Jay (2007). Memory Decreases for Prose, but not for Poetry, Memory \& Cognition, 35, 628-639.

Tse, Peter Ulric, Intriligator, James, Rivest, José \& Cavanagh, Patrick (2004). Attention and the Subjective Expansion of Time, Perception and Psychophysics, 66, 11711189.

Tsur, Reuven (2013). Masculine and Feminine Rhymes. Their Structural Effect, Style, 47(1), 1-24.

--- (2015). Free Verse, Enjambment, Irony. A Case Study, Style, 49(1), 35-45.

Tsur, Reuven, Glicksohn, Joseph \& Goodblatt, Chanita (1991). Gestalt Qualities in Poetry and the Reader's Absorption Style, Journal of Pragmatics, 16(5), 487-500.

van der Henst, Jean-Baptiste \& Sperber, Dan (2004). Testing the Cognitive and Communicative Principles of Relevance. Experimental Pragmatics, eds. Ira A Noveck \& Dan Sperber. New York: Palgrave Macmillan. 141-171.

Wilson, Deirdre \& Matsui,Tomoko (2012). Recent Approaches to Bridging. Truth, Coherence, Relevance. Meaning and Relevance, eds. Deirdre Wilson \& Dan Sperber. Cambridge: Cambridge University Press, 187-209.

Wilson, Timothy D., Centerbar, David B., Kermer, Deborah A., Gilbert, Daniel T. (2005). The Pleasures of Uncertainty. Prolonging Positive Moods in Ways People Do Not Anticipate, Journal of Personality and Social Psychology, 88(1), 5-21. 